\title{
Ethical Leaders and Their Followers: The Transmission of Moral Identity and Moral Attentiveness
}

\author{
Weichun Zhu \\ Linda K. Treviño \\ The Pennsylvania State University
}

\section{Xiaoming Zheng}

Tsinghua University

\begin{abstract}
In the expanding field of ethical leadership research, little attention has been paid to the association between ethical leaders' ethical characteristics (beyond personality) and perceived ethical leadership, and, more importantly, the potential influence of ethical leadership on followers' ethical characteristics. In this study, we tested a theoretical model based upon social cognitive theory (Bandura, 1986) to examine leaders' moral identity and moral attentiveness as antecedents of perceived ethical leadership, and follower moral identity and moral attentiveness as outcomes of ethical leadership. Based upon data from 89 leaders and 460 followers in China, collected at two points in time, we found that leaders' moral identity and moral attentiveness are associated with follower's perceptions of ethical leadership. Ethical leadership is, in turn, associated with their followers' moral identity and moral attentiveness. We found furthermore that ethical leadership mediates the effect of leaders' moral identity on followers' moral identity, but not the effect of leaders' moral attentiveness on followers' moral attentiveness. We discuss the findings, theoretical contributions, practical implications, and future research.
\end{abstract}

KEY WORDS: Ethical Leadership, Moral Identity, Moral Attentiveness

$\mathrm{I}$

NTEREST IN ETHICAL LEADERSHIP HAS BURGEONED in the past decade in part because of ethical scandals in a wide variety of organizations across the globe. At the same time, research has consistently demonstrated the importance of ethical leadership — the demonstration of normatively appropriate conduct through personal actions and interpersonal relationships, and the promotion of such conduct to followers through two-way communication, reinforcement, and decision-making (Brown, Treviño, \& Harrison, 2005: 120)_for influencing follower attitudes and behaviors in a positive ethical direction (Avey, Wernsing, \& Palanski, 2012; De Hoogh \& Den Hartog, 2008; Hansen, Alge, Brown, Jackson, \& Dunford, 2012; Kacmar, Bachrach, Harris, \& Zivnuska, 2011; Mayer, Kuenzi, \& Greenbaum, 2010; Mayer, Kuenzi, Greenbaum, Bardes, \& Salvador, 2009; Schaubreck et al., 2012). 
If ethical leadership is as important as the research suggests it seems essential to understand the characteristics that contribute to followers' perceptions of ethical leadership. Yet, relatively few studies have empirically examined the antecedents of ethical leadership and, those that have, have emphasized Big-Five personality attributes (e.g., Kalshoven, Den Hartog, \& De Hoogh, 2011) rather than more explicit ethics-related attributes. As exceptions, leader cognitive moral development (Jordan, Brown, Treviño, \& Finkelstein, 2013) and leader moral identity (Mayer et al., 2012) were recently found to be related to perceptions of ethical leadership. In this study, we include leader moral identity but we also add a newer construct representing an important ethics-related characteristic, leader moral attentiveness (Reynolds, 2008). We will propose that leaders with higher moral identity and higher moral attentiveness are more likely to be perceived to be ethical leaders by their followers.

Regarding the consequences of ethical leadership, most empirical work has focused on the positive effects of ethical leadership on employees' attitudes, such as follower job satisfaction and affective commitment (Neubert, Carlson, Kacmar, Roberts, \& Chonko, 2009), and job behaviors such as individual and group organizational citizenship behavior (Avey et al., 2011; Mayer et al., 2009), employee voice behavior (Zhu, He, Treviño, Chao, \& Wang, 2015), job performance (Zhu et al., 2015), follower misconduct (Mayer, Kuenzi, \& Greenbaum, 2010), and follower deviance (van Gilsa, van Quaquebekeb, van Knippenbergc, van Dijkec, \& de Cremer, 2015). But research has not yet addressed whether ethical leadership is associated with followers' ethics-related personal characteristics, such as follower moral identity and moral attentiveness.

In this study, we ask whether stronger ethical leadership is associated with an increase in follower's attentiveness to ethical issues and the extent to which they say they think of themselves as moral persons. In sum, we will test the effects of leaders' moral identity and moral attentiveness on ethical leadership, and the effects of ethical leadership on followers' moral identity and moral attentiveness. We will also test ethical leadership as a mediator of those relationships. Figure 1 depicts the theoretical model.

Our research makes multiple contributions. First, we expand understanding of who is more likely to be perceived to be an ethical leader by finding that moral attentiveness serves as an antecedent to perceived ethical leadership. We also

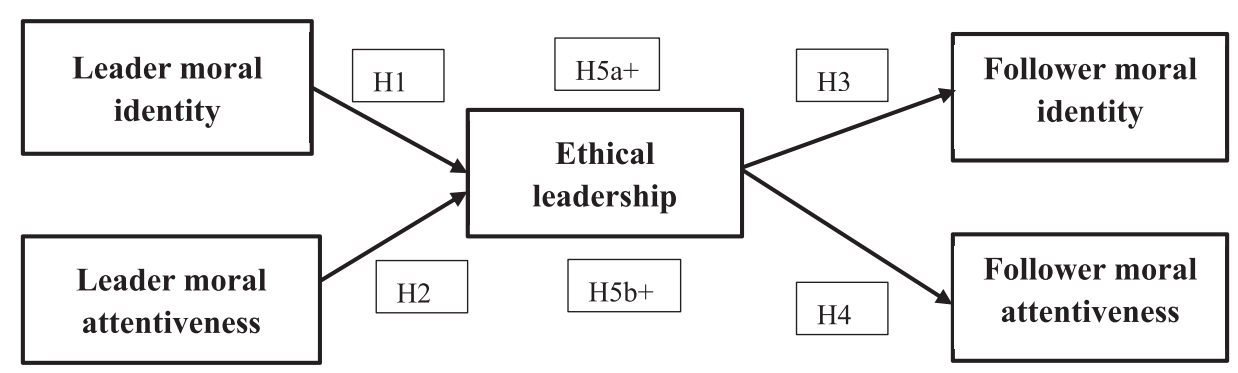

Figure 1: Theoretical Model. 
replicate the finding that leader moral identity serves as an antecedent to ethical leadership as has been previously shown (Mayer et al., 2012). Second, we answer a particularly important question about whether the followers of ethical leaders are stronger on these same characteristics. Our supportive findings suggest that stronger ethical leaders are associated with followers' heightened ethics-related characteristics, meaning that follower moral identity and moral attentiveness that have been considered to be more stable and trait-like in the past can be altered by external stimuli such as strong ethical leadership. These findings seem particularly important both theoretically and empirically because they demonstrate that ethical leaders are able to influence followers' ethical characteristics that drive their attentiveness to ethical issues as well as the way they think of themselves as moral persons. The fact that the ethical characteristics of followers tend to mimic those of their leaders suggests a social cognition (Bandura, 1977, 1986) explanation for the relationship, in keeping with the primary theoretical framework driving the ethical leadership construct.

\section{HYPOTHESES}

Bandura's (1986) social cognitive theory has provided the foundation for much recent behavioral ethics research (Treviño, den Nieuwenboer, \& Kish-Gephart, 2014) including research on moral identity, moral attentiveness, and ethical leadership. Therefore, it offers a useful overarching framework for this study and the relationships we propose. Social cognitive theory emphasizes the importance of individual cognition, self-reflection, and self-regulation, as well as how cognition results from the social environment via attention processes and social learning from models.

\section{Leader's Moral Identity and Ethical Leadership}

Social cognitive theory represents moral identity as a component of one's self concept. Moral identity refers to the extent to which people believe themselves to be ethical and the degree to which moral traits such as being caring, compassionate, fair, friendly, generous, helpful, honest and kind are important and central to their self-definition, including their desire to represent this aspect of themselves to others (Aquino \& Reed, 2002). For those with a strong moral identity, social cognitive theory argues that their moral self-schema is more cognitively accessible and more easily activated (Lapsley \& Lasky, 2001). Moral identity is considered to be critically important to ethical decision making and behavior (Aquino \& Reed, 2002; Blasi, 1984; Hardy \& Carlo, 2005; Weaver, 2006) and has been found to be positively related to pro-social behaviors and negatively related to unethical behaviors such as cheating (Shao, Aquino, \& Freeman, 2008).

Aquino and Reed's (2002) conception of moral identity incorporates two dimensions, symbolization (i.e., the desire to represent oneself to others as moral) and internalization (i.e., the perception of oneself as higher on the above moral characteristics). Moral identity internalization, which has been used in many studies (e.g., Aquino, Freeman, Reed, Lim, \& Felps, 2009; Smith, Aquino, Koleva, \& Graham, 2014), 
represents the degree to which individuals imbed moral traits as an integrative component of their moral self-concept. With high moral identity internalization, individuals avoid unethical behaviors, notice, correct, and deal with those unethical behaviors, and pay attention to how ethical decisions are made (e.g., Aquino \& Reed, 2002; Mayer et al., 2012; Reynolds \& Ceranic, 2007). With high moral identity symbolization, people are motivated to publicly express to others that aspect of themselves that represents their moral identity (Aquino et al., 2009; Aquino \& Reed, 2002).

Aquino and Reed (2002) proposed that moral identity can serve as a self-regulatory mechanism because of the internalized notions of right and wrong that can influence people to act ethically. The motivational power of moral identity arises from peoples' desire for self-consistency (Blasi, 1984, 2004). In order not to experience guilt or other types of negative emotions, individuals with higher levels of moral identity tend to act in ways that are consistent with their moral identity (Aquino et al., 2009; Aquino \& Reed, 2002; Mayer et al., 2012).

Reynolds and Ceranic (2007) noted that moral identity also represents an important link between moral judgment and moral behavior. When facing moral dilemmas, individuals need to select, perceive, interpret and respond to external stimuli. Because moral identity influences ethical decision-making (Rest, Narvaez, Bebeau, \& Thoma, 1999), leaders with a higher level of moral identity can be expected to be more likely to make ethical decisions and act ethically (e.g., Mayer et al., 2012).

We thus propose that leaders with stronger moral identity will be more likely to be perceived to be ethical leaders because such leaders will more likely engage in the normatively appropriate behaviors that are associated with ethical leadership (either because they wish to portray themselves as moral to others or because they think of themselves in moral terms). They will show care and concern for their subordinates and other stakeholders such as customers or business partners and they will make fair and principled decisions. They will engage in and encourage pro-social behavior and will be more likely to notice, discourage and correct unethical behavior in themselves and in others, all attributes of ethical leadership.

Therefore, we hypothesize that:

H1: Leaders' moral identity is positively related to follower perceptions of them as ethical leaders.

\section{Leader's Moral Attentiveness and Ethical Leadership}

While moral identity has recently been associated with perceptions of ethical leadership (Mayer et al., 2012), the connection between leader's moral attentiveness and ethical leadership has not yet been studied. But, scholars have noted that regularly attending to ethical issues is essential to ethical decision making and conduct (Kohlberg, 1976; Treviño, 1986) because when individuals interpret situations as having ethical content and consider how different options affect the concerned parties, they are more likely to behave ethically. One of the critical factors influencing one's sensitivity to and awareness of ethical issues is moral attentiveness, a relatively new construct in the behavioral ethics literature which is defined as "the extent to 
which an individual chronically perceives and considers morality and moral elements in his or her experiences (Reynolds, 2008: 1028)."

Based upon social cognitive theory (Bandura, 1986), Reynolds (2008) proposed that some individuals are cognitively more attentive to ethical issues than others and that individuals' moral attentiveness has a significant effect on how individuals understand and act in their moral worlds. Reynolds argued that moral attentiveness constitutes a distinct cognitive category, or framework, that can make moral information more cognitively accessible. With high moral attentiveness, individuals focus more on morality and use a moral lens to make sense of experience and process incoming stimuli. Thus, individuals use these chronically accessible morality concepts to interpret incoming information, to analyze and reflect on that information, creating a person who is more generally and regularly attentive to the ethical aspects of daily life (Reynolds, 2008). The second aspect of moral attentiveness is a more intentional and reflective aspect wherein individuals consider ethical matters and reflect on their moral experiences. For example, a leader high on moral attentiveness might call on followers to identify a moral issue or issues facing them during a meeting, and then lead a discussion of those issues.

Reynolds (2008) suggested that an individual's level of moral attentiveness was associated with both increased moral awareness (i.e., the recognition that a specific issue is ethics-related) (Jones, 1991) and moral behavior. Thus, leaders who are high in moral attentiveness should be more regularly attentive to the moral dimensions of information they encounter and more likely to reflect on the information with their followers. Because they are likely to bring this attentiveness and resulting moral awareness and ethical behavior to their leadership role, subordinates should be more likely to perceive them as ethical leaders.

H2: Leaders' moral attentiveness is positively related to follower perceptions of them as ethical leaders.

In the following section, we propose that ethical leadership will influence followers' moral identity and moral attentiveness. Neither of these relationships has been previously studied. They are particularly important because they suggest that ethical leaders may have a significant impact on the persons they supervise, beyond the work-related attitudes and behaviors that have been previously studied.

\section{Ethical Leadership and Followers' Moral Identity and Moral Attentiveness}

Based on social cognitive theory's social learning (Bandura, 1977: 1986), Treviño and Brown (2005) argued that ethical leaders influence followers primarily through modeling processes. Behavioral modeling is considered to be one of the most important and effective means for leaders to transmit their values, attitudes, and behaviors to their followers, who learn about desirable traits and behaviors by observing their leaders and then emulating those they find to be legitimate and credible. Therefore, ethical leaders should be able to influence followers' characteristics such as moral identity and moral attentiveness through social learning processes. 
But, can we expect that follower individual differences can differ because of their association with a particular leader? We have long tended to think of individual differences as stable, especially the most heritable ones, such as intelligence and the Big Five personality characteristics (e.g., Costa \& McCrae, 1988). However, even Costa and McCrae, who have been represented as proponents of the immutability of personality traits, have said that they are open to the possibility that personality can change (Costa \& McCrae, 2006). Recent research has explored the notion that rather than being set in "plaster," personality may have "plasticity," leading to the understanding that individual differences (even personality) can and does change (Roberts, Walton, \& Viechtbauer, 2006). For example, researchers have demonstrated the plasticity of personality as a result of work experiences (Roberts, 1997). But, we are not proposing here that ethical leaders can change followers' personality, which we suspect may be more difficult to change than the characteristics we consider in our study. We argue here that followers' moral identity and moral attentiveness are somewhat plastic and therefore, likely subject to social influence, something that the developers of these constructs also propose and as we explain below. We also look to Lord and Brown (2004) who also relied on social cognitive theory (Bandura, 1986) to propose that leaders can have a profound influence on followers' selves by communicating meaning (verbally and non-verbally) in various situations. For example, an ethical leader's routine use of ethical language in a variety of situations should prime and activate followers' moral identities and awareness. In their book, Lord and Brown (2004) review research demonstrating that leaders can influence followers' self-concepts through priming effects and by creating environments that cue and activate aspects of their identities.

Although research has generally treated moral identity as a relatively stable individual difference, Shao, Aquino, and Freeman (2008) also argued that it can develop through social interactions with peers and parents in adolescence. They proposed that, beyond adolescence, moral identity development is affected by institutional contexts such as work contexts. We propose here that one of the most important ethical influences in the work context is a strong ethical leader. Therefore, when employees observe leaders who stand up for doing what is right, especially if the leaders are successful in doing so, their moral identities will be primed and they will be encouraged to think about this aspect of themselves.

Further, from a social learning perspective, followers will be inclined to want to emulate ethical leaders and therefore ascribe more importance to the moral aspects of their own identities. The ethical leader's moral values, preferences, aspirations, emotional responses and behaviors become the targets of emulation, with followers desiring to be good and moral persons themselves-persons who value the moral aspect of their identity. Because they admire and wish to emulate the leader, these followers should come to think of themselves differently, as people for whom the moral aspect of themselves is elevated in importance.

Furthermore, we propose that ethical leaders can influence followers' moral attentiveness because a strong ethical leader directs followers' attention in an ethical direction - to ethical standards, concerns, and complexities, priming them to notice and attend to ethical issues. Although moral attentiveness (like moral identity) has 
been treated as a relatively stable individual difference, Reynolds (1998) argued that moral attentiveness is not fixed and that leaders could be helped to increase their moral attentiveness. Along the same lines, we argue here that the moral attentiveness of followers is quite likely open to influence by strong ethical leaders. Ethical leaders set ethical standards, regularly communicate with followers about ethical issues and give them feedback about ethical decisions. When facing moral challenges or dilemmas at work, ethical leaders raise ethical issues, explain the moral values that guide their decisions and actions, provide constructive and insightful suggestions or feedback to followers, and coach followers on how to deal with ethical dilemmas and how to solve issues in an ethical way. With this repetitive attention to ethical issues from their leader, followers should become more regularly attentive to ethical concerns themselves. Because ethical leaders are legitimate and credible role models, followers will also want to emulate the leader's attentiveness to ethical issues.

In addition, because ethical leaders care a great deal about their people, they are also likely to take an interest in and engage with their followers' ethical growth and development. Ethical leaders are more likely than other leaders to provide ethical mentoring, with followers reciprocating with their trust and attention. As a result, followers of ethical leaders will be more likely to notice and internalize the ethical values, behaviors, and messages being sent by the ethical leader, and incorporate these into their moral selves through increased moral identity and attentiveness.

Thus, we hypothesize that:

H3: Ethical leadership is positively related to followers' moral identity.

H4: Ethical leadership is positively related to followers' moral attentiveness.

\section{The Mediating Role of Ethical Leadership}

To this point, we have hypothesized that leader's moral identity and moral attentiveness are positively related to ethical leadership and that ethical leadership is positively related to followers' moral identity and moral attentiveness. In order to complete our model, we predict that the relationships between leaders' moral characteristics and followers' characteristics are mediated by ethical leadership. We suggest that only when leaders "walk the talk" through ethical leadership behaviors can followers become aware of their thoughts and decision processes, witness their behaviors in a variety of organizational settings and learn from their leader's daily moral talk and actions. In other words, a leader's moral identity and moral attentiveness can only be exemplified to followers through ethical leadership behaviors such as the explicit identification of ethical issues in meetings, conversations about the importance of doing the right thing, fair and principled decisions, and actions taken in response to inappropriate behaviors. Then, via modeling processes, followers mimic ethical leaders, resulting in the enhancement of their own moral identity and attentiveness. Ethical leaders, as moral exemplars, provide a strong basis for followers to emulate their attentiveness to ethical issues and to think differently about themselves, elevating the extent to which morality is more central and important to their identity. Therefore, we expect that ethical leadership behavior will mediate between leaders' 
moral identity and followers' moral identity and between leaders' moral attentiveness and followers' moral attentiveness.

Thus, we hypothesize that:

H5a: Ethical leadership mediates the relationship between leaders' moral identity and followers' moral identity.

H5b: Ethical leadership mediates the relationship between leaders' moral attentiveness and followers' moral attentiveness.

\section{METHODS}

\section{Participants and Procedure}

We collected a total of 89 leader-follower groups from two companies, one in the communication and IT industry, and the other one in the manufacturing industry, through CEO support. The human resources departments in the companies provided us with a full roster of demographic information (such as age, gender, educational level) and work-related information (entry date, job rank, etc.). A structured questionnaire was compiled in English and then translated into Chinese following doubletranslation rules (Sperber, Devellis, \& Boehlecke, 1994). Before the survey, one research assistant explained to the participants the purpose and requirement of the research, ensured the confidentiality of the research process, and collected all of the surveys when completed on site.

To reduce concerns about common method variance (Podsakoff, MacKenzie, \& Podsakoff, 2012), we collected data from two different sources at two time points with an interval of three weeks. At Time 1, we asked 548 employees to report their immediate supervisors' ethical leadership behaviors, and we asked 99 immediate supervisors of these employees to report their own moral identity and moral attentiveness. The purpose of the first wave is to test the antecedents of ethical leadership. At Time 2, we distributed surveys to the same group of employees, and they reported their own moral identity and moral attentiveness. The purpose of the second wave is to test the consequences of ethical leadership. Followers responded to questions regarding their moral identity and moral attentiveness. After matching the cases of Time 1 and Time 2, we arrived at the final sample of 460 followers, with a response rate of $84.94 \%$, and 89 supervisors, with a response rate of $89.90 \%$. Every leader has an average of 3 to 10 (Mean $=5.17)$ followers. We got strong support and endorsement from the CEOs of these two firms, which helped us to obtain a higher response rate. It is not surprising that response rate is high when there is a support from the executive leaders in a company (Baruch \& Holtom, 2008).

In the leader sample, $61.8 \%$ were male and $38.2 \%$ were female. Thirty-two point six percent were between 25 and 35; $48.3 \%$ were between 35 and 45; $19.1 \%$ were above 45 . The majority $(96.7 \%)$ held a college degree or above. The supervisor respondents had an average working tenure of 18.11 years and an average company tenure of 12.46 years.

In the follower sample, $44.3 \%$ were male and $55.7 \%$ were female; $15.6 \%$ were under $25 ; 54.8 \%$ were between 25 and $35 ; 17.8 \%$ were between 35 and 45; 
$11.8 \%$ were above 45 . The majority $(90.0 \%)$ held a college degree or above. The follower respondents had an average working tenure of 12.34 years and an average company tenure of 9.79 years.

\section{Measures}

Ethical leadership. Ethical leadership was measured using Brown et al.'s (2005) 10-item 5-point Likert scale. Employees were asked to consider their immediate supervisors and indicate the extent to which they agree or disagree with statements about their supervisors. Sample items include, "listens to what employees have to say"; and "disciplines employees who violate ethical standards." The Cronbach's alpha score is .91. The CFA results using M-plus (Muthen \& Muthen, 2010) showed acceptable indexes: $\chi^{2}=184.43, d f=35, p<.01, \mathrm{CFI}=.94$, RMSEA $=.10$, $\mathrm{SRMR}=.04$. Although the RMSEA score is slightly higher than the recommended score, it is still within the acceptable range of up to .10 (Browne \& Cudeck, 1993).

Moral identity. We measured moral identity using Aquino and Reed's (2002) 10-item 5-point Likert moral identity scale, including both the "internalization" and "symbolization" sub-dimensions. Sample items were, "Being someone who has these characteristics is an important part of who I am (internalization)" and "The types of things I do in my spare time (e.g., hobbies) clearly identify me as having these characteristics (symbolization)." One item, "I would be ashamed to be a person who has these characteristics ( R )", was removed from the analysis due to its low loading value smaller than .30. Cronbach's alpha scores are .75 and .86 for the leader and follower samples.

Because we were not predicting different theoretical relationships for the two dimensions, and to simplify our model for parsimony purposes, we treated moral identity as a 2nd order factor, as others have done (e.g., Brebels, De Cremer, Van Dijke, \& Van Hiel, 2011) and as our data suggested would be appropriate. To support our treatment of moral identity as a $2^{\text {nd }}$ order factor, we ran a CFA. The CFA results showed that the goodness-offit indices of the $2^{\text {nd }}$ order model $\left(\chi^{2}=148.73, d f=25, \mathrm{p}<.01, \mathrm{CFI}=.91, \mathrm{RMSEA}=.10\right.$, $\mathrm{SRMR}=.07)$ are significantly better $\left(\right.$ delta $\chi^{2}=5.95$, delta $\left.d f=1, \mathrm{p}<.01\right)$ than the 2 -factor model $\left(\chi^{2}=154.68, d f=26, p<.01, \mathrm{CFI}=.91, \mathrm{RMSEA}=.10, \mathrm{SRMR}=.07\right)$. According to Bollen (1989), a second-order model is preferable to a first-order model when both models fit the data essentially the same in terms of fit, because a higher order model allows for covariation among first-order factors and accounts for the corrected errors that are common in first-order models. Although the RMSEA score is slightly higher than the recommended score, it is still within the acceptable range of up to .10 (Browne \& Cudeck, 1993).

Moral attentiveness. We measured moral attentiveness using Reynolds's (2008) 12-item, 7-point Likert Moral Attentiveness Scale. It includes both perceptual (7 items) and reflective sub-dimensions (5 items). Sample items were "Many of the decisions that I make have ethical dimensions (perceptual aspect)" and "I think about the morality of my actions almost every day (reflective aspect)." One item measuring the perceptual aspect, "I rarely face ethical dilemmas ( R )", was removed from the analysis due to its low loading value smaller than .30. Cronbach's alpha scores are .84 and .92 for leader and follower samples. 
Again, in the interest of parsimony, because we did not theorize different relationships for the two sub-dimensions, and because these two sub-dimensions have been demonstrated to be highly correlated and to have similar relationship patterns with other theoretically discriminant and convergent measures (Reynolds, 2008), we created a general scale of moral attentiveness as others have done (e.g., van Gils et al., 2015; Whitaker \& Godwin, 2013). We ran a CFA to support our decision to treat moral attentiveness as a general scale. The CFA results showed that the goodness-of-fit indices of the 2nd order model $\left(\chi^{2}=80.74, d f=42, p<.01, \mathrm{CFI}=.96, \mathrm{RMSEA}=.05\right.$, SRMR $=.06)$ are quite similar $\left(\right.$ delta $\chi^{2}=1.92$, delta $\left.d f=1, p>.05\right)$ to the 2-factor model $\left(\chi^{2}=82.66, d f=43, p<.01, \mathrm{CFI}=.96, \mathrm{RMSEA}=.05, \mathrm{SRMR}=.06\right)$. This is also consistent with Bollen's suggestions (1989) as noted above.

\section{RESULTS}

\section{Descriptive Statistics}

Table 1 reports the means, standard deviations, correlations and reliability coefficients of all variables used in the study. We found that leaders' moral attentiveness $(r=.21$, $p<.01)$, and moral identity $(r=.23, p<.01)$ were positively related to ethical leadership. Similarly, ethical leadership was positively related to followers' moral attentiveness $(r=.28, p<.01)$, and moral identity $(r=.34, p<.01)$. Additionally, the coefficients between leaders' moral attentiveness and followers' moral attentiveness $(r=.33, p<.01)$, between leaders' moral identity and followers' moral identity $(r=.10, p<.05)$, were statistically significant. We also calculated skewness and kurtosis statistics for all variables in Table 1; none indicated violations of normality assumptions.

\section{Hypothesized Model}

The M-PLUS program provides the correct parameter estimates and standard errors, and yields more accurate Type I error rates than non-hierarchical methods. M-PLUS not only provides a general way to deal with non-independence of ratings of ethical leadership among different followers within one unit under the leadership of the same manager, it also permits intercepts and slopes to vary randomly across leader clusters (Preacher, Zyphur, \& Zhang, 2010). Therefore, we used multilevel path analysis

Table 1: Descriptive Statistics, Reliability Coefficients and Correlations amongst Study Variables

\begin{tabular}{llrlllll}
\hline \hline Variable & Mean & S.D. & $\mathbf{1}$ & $\mathbf{2}$ & $\mathbf{3}$ & $\mathbf{4}$ & $\mathbf{5}$ \\
\hline 1. Leader moral attentiveness & 4.52 & 1.18 & .84 & & & & \\
2. Leader moral identity & 4.55 & .43 & $.26^{* *}$ & .75 & & & \\
3. Ethical leadership & 4.13 & .71 & $.21^{* *}$ & $.23^{* *}$ & .92 & & \\
4. Follower moral attentiveness & 4.47 & 1.25 & $.33^{* *}$ & $.24 * *$ & $.28^{* *}$ & .88 & \\
5. Follower moral identity & 4.41 & .63 & .07 & $.10^{*}$ & $.34^{* *}$ & $.22^{* *}$ & .87 \\
\hline \hline
\end{tabular}

Note. $\mathrm{N}=460$.

$* p<.05 ; * * p<.01 ; * * * p<.001$

Values shown in the diagonal are Alpha reliability scores. 
model to accommodate the cross-level nature of this study and to model top-down relationships (Preacher et al., 2010). The multilevel path analysis model decomposes the variance of a variable into the within-group variance and the between-group variance (Muthén \& Asparouhov, 2009). The multilevel path analysis model allows modeling the different variance components independently at different levels. At the within-group level, variables can have random intercepts and random slopes, can differ between groups. At the between-group level, these random intercepts are latent variables with each team member as the indicators.

The multilevel path analysis avoids such problems as conflated within- and between-group relationships and is able to calculate the indirect effects more precisely than the traditional multilevel approach (Nohe, Michaelis, Menges, Zhang, \& Sonnta, 2013; Preacher et al., 2010). The two-level model is able to partition the variance of a variable in clustered data into two orthogonal latent components (i.e., the between component and the within component) (Asparouhov \& Muthen, 2006). The level 2 variables (leader moral identity and moral attentiveness) have only between-group variance. Level 1 variables (ethical leadership, follower moral identity, and moral attentiveness) usually have both between and within components (Preacher et al., 2010).

In our proposed model, independent variables such as leaders' moral identity, and moral attentiveness are assessed at level 2, the mediator ethical leadership is assessed at level 1 but with both within-group and between-group variances, and the outcomes such as followers' moral identity, and moral attentiveness are assessed at level 1. Therefore, in our model, X (leader moral identity, and moral attentiveness) are assessed at Level 2 and M (i.e., ethical leadership) and Y (i.e., follower moral identity, and moral attentiveness) are assessed at Level 1 (i.e., 2-1-1 design). We also calculated the intra-class correlation coefficients (ICCs) for ethical leadership $(\operatorname{ICC}(1)=.31, p<.01 ; \operatorname{ICC}(2)=.71, p<.01)$. The results show that $31 \%$ of variance resides in the between-group level, which means that between-level (i.e., group level) variance of ethical leadership cannot be ignored. The ICC(2), which represents that the group mean has a reliability higher than the recommended level (Bliese, 2000), shows that it is appropriate to treat ethical leadership as a grouplevel construct. Therefore, it is appropriate to categorize the total variance of ethical leadership into the within-group and between-group components.

Nevertheless, through the command of "Cluster" M-PLUS, we are able to adjust for clustering or classification in data analysis taking non-independence of observations into account (Bliese, 2000; MacKinnon, Lockwood, \& Williams, 2004; Preacher \& Hayes, 2008). Doing so offers more accurate coefficient estimation and significance testing by controlling for the non-independence effect at the group level (Bliese, 2000; Muthén \& Muthén, 1998-2010), which also means that the confounding influence due to the fact that employees are in the same organization (note: we have two firms) is also controlled for.

We conducted the path analysis using Mplus 6.0 (Muthén \& Muthén, 1998-2010) with robust maximum likelihood (MLR) estimation. The fit indexes of the proposed theoretical model are: $\chi^{2}=4.36, d f=2, \mathrm{CFI}=.97, \mathrm{RMSEA}=.05, \mathrm{SRMR}$ (within) $=$ .00, SRMR $($ between $)=.07$. Although the SRMR (between) is slightly higher than 
the recommended score, it is still within the acceptable range of up to .10 (Browne, \& Cudeck, 1993). Also, the score of $\chi^{2} / \mathrm{df}(2.18)$ falls below the adequate fit range of less than 5 (Marsh \& Hocevar, 1985). Table 2 shows the regression path coefficients, supporting hypotheses 1 through 4 .

Finally, to test for mediation (Hypothesis 5), we followed Mackinnon, Lockwood, Hoffman, West, and Sheets (2002) and calculated the product of coefficients with M-PLUS 6.0 (Muthén \& Muthén, 1998-2010). The statistically significant indirect path coefficient implies that the relationship between the predictor and the outcome variables occur through the mediator (Iacobucci, Saldanha, \& Deng, 2007; Mackinnon et al., 2002; Preacher \& Hayes, 2008). The indirect effect corresponding to the chain relationship (leader moral identity - ethical leadership - follower moral identity) is significant $(\beta=.077$, standard error $=.043, p<.05)$, as shown in Table 3 , and the direct relationship between leader moral identity and follower moral identity is not $(\beta=.084$, standard error $=.082, p>.05)$, which is no longer considered a necessary condition for claiming a mediating effect by some scholars (e.g., Kenny, 2014; MacKinnon, Fairchild, \& Fritz, 2007). Therefore, H5a, which posits that ethical leadership mediates the relationship between leaders' moral identity and followers' moral identity, was supported, which means that ethical leadership is a full mediator. The indirect effect corresponding to the chain relationship (leader moral attentiveness - ethical leadership - follower moral attentiveness) is not significant $(\beta=.02, p>.05)$ as shown in Table 3. Therefore, H5b, which posits that ethical leadership mediates the relationship between leaders' moral attentiveness and followers' moral attentiveness, was not supported. However, the direct relationship between leader moral attentiveness and follower moral attentiveness is significant $(\beta=.29$, $p<.01$ ). To summarize, we found that ethical leadership mediates only the relationship between leader moral identity and follower moral identity, but not the relationship between leader moral attentiveness and follower moral attentiveness.

We conducted further analysis by reversing the relationship paths among these variables. Specifically, we treated follower moral identity and follower moral attentiveness as IVs, and ethical leadership, leader moral identity and leader moral attentiveness as DVs. This model exhibits a poorer model fit $\left(\chi^{2}=29.91, d f=6\right.$, $\mathrm{CFI}=.73, \mathrm{RMSEA}=.09, \mathrm{SRMR}($ within $)=.04, \mathrm{SRMR}($ between $)=.21)$ compared

Table 2: Structural Equation Path Coefficients

\begin{tabular}{lllll}
\hline \hline & Est. & S.E. & p-value & Significant \\
\hline Leader moral attentiveness - Ethical leadership & $.08^{*}$ & .04 & $<.05$ & YES \\
Leader moral identity- Ethical leadership & $.27^{* *}$ & .10 & $<.01$ & YES \\
Ethical leadership - Follower moral attentiveness & $.26^{* *}$ & .08 & $<.01$ & YES \\
Ethical leadership-Follower moral identity & $.29 * *$ & .06 & $<.01$ & YES \\
Leader moral attentiveness - Follower moral identity & $.29 * *$ & .09 & $<.01$ & YES \\
Leader moral identity - Follower moral identity & .08 & .08 & $>.10$ & NO \\
\hline \hline
\end{tabular}

Note. $\mathrm{N}=460$. The standardized coefficients are reported.

$* p<.05 ; * * p<.01$ (1- tailed) 
Table 3: Mediation of the Effect of Leader Moral Characteristics on Follower Moral Characteristics through Ethical Leadership

\begin{tabular}{lcccc}
\hline \hline & Est. & S.E. & P-Value & Significant \\
\hline $\begin{array}{l}\text { Leader moral identity- Ethical leadership- Follower moral } \\
\quad \text { identity }\end{array}$ & .08 & .03 & .01 & YES \\
$\quad \begin{array}{l}\text { Leader moral identity- Ethical leadership-Follower moral } \\
\quad \text { attentiveness }\end{array}$ & .07 & .03 & .05 & YES \\
$\quad \begin{array}{l}\text { Leader moral attentiveness-Ethical leadership - Follower } \\
\quad \text { moral identity }\end{array}$ & .02 & .01 & .05 & YES \\
$\quad \begin{array}{l}\text { Leader moral attentiveness-Ethical leadership-Follower } \\
\text { moral attentiveness }\end{array}$ & .02 & .01 & $>.05$ & NO \\
\hline \hline
\end{tabular}

Note. $\mathrm{N}=460$. The standardized coefficients are reported.

$* p<.05 ; * *<.01$ (1- tailed)

to the hypothesized model. This analysis casts doubt on the alternative explanation that followers with higher levels of moral attentiveness and moral identity rate their leader higher on ethical leadership.

\section{DISCUSSION}

In this research we attempted to answer the question whether ethics-related characteristics of leaders are associated with follower perceptions of their ethical leadership and whether followers of ethical leaders differ in terms of their ethics-related characteristics because of their association with an ethical leader. Our research suggests that the answer is yes. We examined two important social cognition-based individual antecedents of ethical leadership, leader moral identity and leader moral attentiveness (the latter had not been previously studied). We also studied two follower ethics-related outcomes of ethical leadership, neither of which had been studied previously. Our results support the hypotheses that leaders' moral identity and moral attentiveness are associated with follower perceptions of their ethical leadership, which, in turn, are associated with followers' increased moral identity and moral attentiveness. Thus, followers of ethical leaders are higher in moral attentiveness and moral identity, meaning that they are more chronically attentive to moral issues and they say that moral identity is a more important part of their overall self-concept. Ethical leadership mediates this relationship for moral identity but not for moral attentiveness.

\section{Implications for Research}

This research makes a number of contributions. First, we advance the developing field of ethical leadership by expanding its nomological network to include moral attentiveness as an antecedent and both follower moral identity and moral attentiveness as outcomes. As to the antecedents, only a handful of studies (e.g., Mayer et al., 2012) have examined the antecedents of ethical leadership. But, the focus has been mostly on personality traits with little attention to ethics-related leader characteristics, such as moral identity and moral attentiveness (see Mayer et al., 2012 and 
Jordan et al., 2013 for exceptions). We tested the association of leaders' moral identity, and moral attentiveness with ethical leadership, expanding the answer to the question, who is more likely to be perceived as an ethical leader. Findings show that a leader's moral identity and moral attentiveness are positively related to follower perceptions of their ethical leadership. Our findings also extend previous research on moral attentiveness (Reynolds, 2008) and moral identity (e.g., Aquino \& Reed, 2002; Aquino et al., 2009) and demonstrate the two variables' value as predictors of ethical leadership. Leader moral identity and moral attentiveness concern the leader's self-definition and associated schemas (in the case of moral identity) and attention mechanisms (in the case of moral attentiveness), both of which rely on social cognitive mechanisms (Aquino \& Reed, 2002; Bandura, 1986; Reynolds, 2008).

A particularly unique aspect of our study is the proposal and finding that the followers of ethical leaders (who are higher on moral identity and moral attentiveness) are themselves higher on moral identity and moral attentiveness, suggesting a kind of moral uplifting role for ethical leaders who act as attractive, legitimate, and credible role models for their followers (Burns, 1978; Bass, \& Steidlmeier, 1999; Brown \& Treviño, 2006; Zhu, Avolio, Riggio, \& Sosik, 2011) and who likely prime ethical self-concept and draw attention to ethical issues, activating followers' ethical schemas or creating new ones (Lord \& Brown, 2004). The path coefficients for these two relationships are almost identical, suggesting that the followers of stronger ethical leaders are similarly elevated across these two dimensions. Again, relying on social cognitive theory (Bandura, 1986) we proposed that it is primarily through social cognitive processes, including modeling that followers of ethical leaders become more attentive to moral issues that arise, and think of themselves more as moral people. Both moral attentiveness and moral identity have been thought of primarily as stable, trait-like characteristics. But, our research suggests that both are potentially malleable through exposure to a strong ethical leader.

An interesting finding concerns the mediating role of ethical leadership. As indicated above, we found that ethical leadership fully mediates the effect of leader moral identity on follower moral identity, but does not mediate the effect of leader moral attentiveness on follower moral attentiveness. This finding suggests that the nature of the relationship between leaders' and followers' ethics-related characteristics differs for these two characteristics. Our findings suggest that a leader's moral identity may need to be demonstrated more clearly and explicitly by ethical leadership behaviors in order to be noticed and cognitively processed by followers such that it affects followers' own moral identity. By contrast, the moral attentiveness of followers appears to be more open to direct influence by the ethical leader. Moral attentiveness may not need to be demonstrated as explicitly by managers' ethical leadership behaviors because leader moral attentiveness is inherently more obvious, as shown in the direct relationship between leader moral attentiveness and follower moral attentiveness. This makes sense because, from a social learning (Bandura, 1986) perspective, followers are likely to attend to whatever leaders are attending to and learn, over time, to attend more to ethical issues themselves. Moral attentiveness may also be inherently more plastic because it does not implicate followers' identities, but only what they attend to. 
By contrast, we found no direct effect of leader moral identity on follower moral identity. This also makes sense because moral identity is less likely to be apparent to followers unless it is explicitly demonstrated through a variety of ethical leadership behaviors. Followers of a strong ethical leader who does all of the things strong ethical leaders do (e.g., treat employees well, make principled and fair decisions, hold everyone accountable to high standards) may be more inclined to align their own identities with that of the strong ethical leader. But, these are questions for future research. This investigation has been fruitful for exploring how leaders' individual moral characteristics can directly and indirectly influence followers' moral characteristics and has opened the door to further research.

In other recent work, follower moral attentiveness was found to moderate the relationship between ethical leadership and follower unethical behavior (van Gils et al., 2015). Those followers who were more morally attentive were more likely to engage in deviant behaviors in response to an unethical leader. Future studies should examine the moderating role of follower moral attentiveness in ethical leadership outcomes as well. Similarly, follower moral identity may moderate such relationships.

Rather than treating moral identity and moral attentiveness exclusively as stable trait-like constructs, our research suggests that we should also consider that they are somewhat malleable individual characteristics that can be influenced by significant others in the work context such as strong ethical leaders. Future research should conduct investigations over time to determine whether these leader influences "stick" with followers. In other words, do followers who have worked for a strong ethical leader maintain these ethical characteristics (higher moral identity and moral attentiveness) over time? And, what happens when a new leader arrives or the employee moves on to a new work group or organization? Are strong ethical leaders capable of affecting lasting changes in their followers? Lord and Brown (2004) noted that less research exists on the enduring effects of leaders on followers' self concepts, making longitudinal research on this question even more important.

\section{Implications for Practice}

Our research has several practical implications. First, given the importance of ethical leadership found in this and other studies, it is worthwhile for organizations to utilize human resource practices such as selection, coaching, mentoring, training and other leader development tools to increase the level of ethical leadership in their organizations. Organizations should be able to assess managerial candidates' moral attentiveness and moral identity by using available scales. Second, organizations may be able to develop training or other programs aimed at enhancing leader moral identity and moral attentiveness. For example, Reynolds (1998) suggested that managers could be helped to develop critical moral reflection by being encouraged to think about the moral complexities they face and examine the underlying social, cultural, and other factors that can possibly influence moral attentiveness. Our research suggests that if leaders are more attentive to moral issues, their followers will be as well. So, future research should consider whether and how leaders can be developed in this way. 
Additionally, we learned that ethical leadership is important if we want to influence employees to think more about ethical issues, and to think of themselves as moral agents. Therefore, leaders must be made to understand the importance of their ethical role modeling not just for followers' attitudes and behaviors, but also for those followers as ethical persons. Whether the increased moral identity and moral attentiveness that comes from one's association with an ethical leader is lasting and continues beyond this association remains a question for future research. Perhaps it can be undone by a subsequent leader who is either more neutral or even unethical or abusive. Or, perhaps, once having a stronger moral identity and moral attentiveness, followers would strengthen their ethical resolve and courage in the face of unethical leadership in the future.

\section{Strengths and Limitations}

This study has a number of strengths. For example, we identified an additional ethics-related individual difference (e.g., moral attentiveness) as an antecedent for ethical leadership. Perhaps more importantly, we identified follower ethics-related outcomes that are associated with ethical leadership (moral identity and moral attentiveness). Regarding methods, we administered questionnaires to multiple parties (e.g. supervisors and followers) to reduce same source bias (Podsakoff, MacKenzie, Lee, \& Podsakoff, 2003). We also collected data at two time points for leadership variables and follower outcome variables separately. Thus, cross sectional data bias was mitigated. In the first wave, leaders rated their own moral identity and moral attentiveness while followers in each work group rated their leader on ethical leadership. In the second wave, followers responded to questions regarding their moral identity and moral attentiveness. However, despite collecting data at two points in time, we cannot infer causality. For example, followers who have higher levels of moral attentiveness may have noticed and identified with leaders' ethical behaviors more and thus, rated the ethical leadership of their manager higher. In this regard, it would be ideal to collect data at three points in time, i.e. leaders reporting their moral identity/attentiveness at time 1, followers rating their managers' ethical leadership at time 2 , and followers reporting their own moral identity/attentiveness at time 3 .

Also, taking an attraction-selection-attrition (ASA) perspective (Schneider, 1987), employees with stronger ethical characteristics may have been attracted to ethical leaders with these same characteristics or leaders high on these characteristics may have selected followers higher on these characteristics. However, our understanding and experience of work organizations suggests that followers rarely get the opportunity to select their supervisors and supervisors are looking for a broad array of characteristics beyond ethical ones. We also believe that the social cognitive perspective is more logical and more consistent with previous work in these areas. Nevertheless, future research should pursue experimental or longitudinal approaches to further investigate these relationships.

Further, it is possible that ethical leaders influence followers with middle levels of moral identity and moral awareness more than those with extremely low levels of moral identity and moral awareness. This is because those followers with middle 
levels of moral identity and moral attentiveness may aspire to develop their moral selves more than those with lower levels. All of these questions deserve future research exploration.

Although we relied primarily on social cognitive theory (Bandura, 1986) to guide the development of hypotheses in this study, much remains unknown about the social cognitive processes at work such as priming and modeling. Future work should also delve more deeply into these influencing mechanisms regarding how ethical leadership develops followers' moral identity and moral attentiveness.

A final strength of this paper is that we conducted this study in the Chinese context. Because research on ethical leadership in China remains sparse, this research contributed to cross-cultural studies on ethical leadership through finding that managers' ethical characteristics are associated with perceived ethical leadership, which in turn, are associated with followers' ethical characteristics. In this regard, we are extending earlier work on ethical leadership in a different cultural context (Whetten, 2009). In the future, it might be helpful to collect additional cultural variables (e.g., collectivism) that might influence or moderate these relationships.

\section{CONCLUSION}

The present study helped to expand the answers to two questions: Who is more likely to be perceived to be an ethical leader and, more importantly, are ethical leaders likely to have an impact on their followers as moral people? We answered the first question by finding that both leader moral identity and moral attentiveness are associated with follower perceptions of ethical leadership. We began to answer the second question by finding that ethical leadership is positively related to followers' moral identity and moral attentiveness. We also learned that the relationship between leader and follower moral attentiveness is a direct relationship while the relationship between leader and follower moral identity is mediated by ethical leadership, a difference we explore in our discussion. We hope this study contributes to the increasing awareness of the importance of ethical leadership and increases attention to how to increase it for the moral elevation of followers.

\section{ACKNOWLEDGEMENTS}

The authors would like to thank the action editor Bruce Barry and the three anonymous reviewers for their very helpful and constructive comments and guidance on earlier versions of this manuscript. This project was funded in part by the Humanity and Social Science Foundation of Ministry of Education of China (No 11YJA630212).

\section{REFERENCES}

Aquino, K., \& Reed, A. 2002. The self-importance of moral identity. Journal of Personality and Social Psychology, 83(6): 1939-1315.

Aquino, K., Freeman, D., Reed, A., Lim, V. K. G., \& Felps, W. 2009. Testing a socialcognitive model of moral behavior: The interactive influence of situations and moral identity centrality. Journal of Personality and Social Psychology, 97(1): 123-141. 
Asparouhov, T., \& Muthen, B. 2006. Constructing covariates in multilevel regression (Mplus Web Notes No. 11). http://www.statmodel.com.

Avey, J. B., Wernsing, T. S., \& Palanski, M. E. 2012. Exploring the process of ethical leadership: The mediating role of employee voice and psychological ownership. Journal of Business Ethics, 107(1): 21-34.

Bandura, A. 1977. Social learning theory. Englewood Cliffs, NJ: Prentice Hall. . 1986. Social foundations of thought and action. Englewood Cliffs, NJ: Prentice Hall.

Baruch, Y., \& Holtom, B. C. 2008. Survey response rate levels and trends in organizational research. Human Relations, 61(8): 1139-1160.

Bass, B. M., \& Steidlmeier, P. 1999. Ethics, character and authentic transformational leadership behavior. The Leadership Quarterly, 10(2): 181-217.

Blasi, A. 1984. Moral identity: Its role in moral functioning. In Kurtines, W. \& Gewirtz, J. (Eds.), Morality, moral behavior and moral development: 128-139. New York: Wiley. . 2004. Moral functioning: Moral understanding and personality. Mahwah, NJ: Lawrence Erlbaum Associates Publishers.

Bliese, P. D. 2000. Within-group agreement, non-independence, and reliability: Implications for data aggregation and analysis. In Klein, K. J. \& Kozlowski, S. W. (Eds.), Multilevel theory, research, and methods in organizations: Foundations, extensions and new directions: 349-381. San Francisco, CA: Jossey-Bass.

Bollen, K. A. 1989. Structural equations with latent variables. New York: Wiley.

Brebels, L., De Cremer, D., Van Dijke, M., \& Van Hiel, A. 2011. Fairness as social responsibility: A moral self-regulation account of procedural justice enactment. British Journal of Management, 22: S47-S58.

Browne, M., \& Cudeck, R. 1993. Alternative ways of assessing model fit. In Bollen, K. \& Long, J. (Eds.), Testing Structural Equation Models: 136-161. Newbury Park, CA: Sage.

Brown, M. E., \& Treviño, L. K. 2006. Ethical leadership: A review and future directions. The Leadership Quarterly, 17(6): 595-616.

Brown, M. E., Treviño, L. K., \& Harrison, D. A. 2005. Ethical leadership: A social learning perspective for construct development and testing. Organizational Behavior and Human Decision Processes, 97(2): 117-134.

Burns, J. M. 1978. Leadership. New York: Harper \& Row.

Costa, P. T., \& McCrae, R. R. 1988. Personality in adulthood - a 6-year longitudinal study of self reports and spouse ratings in the Neo Personality Inventory. Journal of Personality and Social Psychology, 54: 853-863.

2006. Age changes and their origins: Comment on Roberts, Walton, and Viechtbauer. Psychological Bulletin, 132: 26-28.

De Hoogh, A. H. B., \& Den Hartog, D. N. 2008. Ethical and despotic leadership, relationships with leader's social responsibility, top management team effectiveness and subordinates' optimism: A multi-method study. The Leadership Quarterly, 19(3): 297-311.

Eisenberg, N. 2000. Emotion, regulation, and moral development. Annual Review of Psychology, 51(1): 665-697.

Hannah, S. T., Avolio, B. J., \& May, D. R. 2011. Moral maturation and moral conation: A capacity approach to explaining moral thought and action. Academy of Management Review, 36(4): 663-685.

Hansen, S., Alge, B., Brown, M., Jackson, C., \& Dunford, B. 2012. Ethical leadership: Assessing the value of a multi-foci social exchange perspective. Journal of Business Ethics, 96: 1-15. 
Hardy, S. A., \& Carlo, G. 2005. Identity as a source of moral motivation. Human Development, 48(4): 232-256.

Iacobucci, D., Saldanha, N., \& Deng, X. 2007. A meditation on mediation: Evidence that structural equations models perform better than regressions. Journal of Consumer Psychology, 17(2): 140-154.

Jones, T. M. 1991. Ethical decision making by individuals in organizations: An issuecontingent model. Academy of Management Review, 16(2): 366-395.

Jordan, J., Brown, M. E., Treviño, L. K., \& Finkelstein, S. 2013. Someone to look up to: Executive-follower ethical reasoning and perceptions of ethical leadership. Journal of Management, 39(3): 660-683.

Kacmar, K. M., Bachrach, D. G., Harris, K. J., \& Zivnuska, S. 2011. Fostering good citizenship through ethical leadership: Exploring the moderating role of gender and organizational politics. Journal of Applied Psychology, 96(3): 633-642.

Kalshoven, K., Den Hartog, D., \& De Hoogh, A. 2011. Ethical leader behavior and big five factors of personality. Journal of Business Ethics, 100: 349-366.

Kenny, D. A. 2014. Mediation. http://davidakenny.net/cm/mediate.htm. Accessed December $24,2014$.

Kohlberg, L. 1969. Stage and sequence: The cognitive developmental approach to socialization. In Goslin, D. A. (Ed.), Handbook of socialization theory and research: $347-480$. Chicago, IL: Rand McNally.

. 1976. Moral stages and moralization: The cognitive-development approach. In Likona, Thomas (Eds.), Moral development and behavior: Theory, research, and social issues: $31-53$. Austin, TX: Holt, Rinehart \& Winston.

Kuhnert, K. W., \& Lewis, P. 1987. Transactional and transformational leadership: A constructive/developmental analysis. Academy of Management Review, 12(4): 648-657.

Lapsley, D. K., \& Lasky, B. 2001. Prototypic moral character. Identity, 1: 345-363.

MacKinnon, D. P., Fairchild, A. J., \& Fritz, M. S. 2007. Mediation analysis. Annual Review of Psychology, 58: 593-614.

MacKinnon, D. P., Lockwood, C. M., Hoffman, J. M., West, S. G., \& Sheets, V. 2002. A comparison of methods to test mediation and other intervening variable effects. Psychological Methods, 7(1): 83-104.

MacKinnon, D. P., Lockwood, C. M., \& Williams, J. 2004. Confidence limits for the indirect effect: Distribution of the product and resampling methods. Multivariate Behavioral Research, 39(1): 99-128.

Marsh, H. W., \& Hocevar, D. 1985. Application of confirmatory factor analysis to the study of self-concept: First- and higher order factor models and their invariance across groups. Psychological Bulletin, 97(3): 562-582.

Mayer, D. M., Aquino, K., Greenbaum, R. L., \& Kuenzi, M. 2012. Who displays ethical leadership, and why does it matter? An examination of antecedents and consequences of ethical leadership. Academy of Management Journal, 55(1): 151-171.

Mayer, D. M., Kuenzi, M., Greenbaum, R., Bardes, M., \& Salvador, R. B. 2009. How low does ethical leadership flow? Test of a trickle-down model. Organizational Behavior and Human Decision Processes, 108(1): 1-13.

Mayer, D., Kuenzi, M., \& Greenbaum, R. 2010. Examining the link between ethical leadership and employee misconduct: The mediating role of ethical climate. Journal of Business Ethics, 95: 7-16.

Muthén, B., \& Asparouhov, T. 2009. Multilevel regression mixture analysis. Journal of the Royal Statistical Society: Series A: Applied Statistics, 172: 639-657. 
Muthén, L. K. \& Muthén, B. O. 1998-2010. Mplus User's Guide (5 ${ }^{\text {th }}$ edition). Los Angeles, CA: Muthén \& Muthén.

Neubert, M. J., Carlson, D. S., Kacmar, K. M., Roberts, J. A., \& Chonko, L. B. 2009. The virtuous influence of ethical leadership behavior: Evidence from the field. Journal of Business Ethics, 90(2): 157-170.

Nohe, C., Michaelis, B., Menges, J. I., Zhang, Z., \& Sonntag, K. 2013. Charisma and organizational change: A multilevel study of perceived charisma, commitment to change, and team performance. The Leadership Quarterly, 24(2): 378-389.

Podsakoff, P. M., MacKenzie, S. B., Lee, J. L., \& Podsakoff, N. P. 2003. Common method biases in behavioral research: A critical review of the literature and recommended remedies. Journal of Applied Psychology, 88(5): 879-903.

Podsakoff, P. M., MacKenzie, S. B., \& Podsakoff, N. P. 2012. Sources of method bias in social science research and recommendations on how to control it. Annual Review of Psychology, 63: 539-569.

Preacher, K. J., \& Hayes, A. F. 2008. Asymptotic and resampling strategies for assessing and comparing indirect effects in multiple mediator models. Behavior Research Methods, 40(3): 879-891.

Preacher, K. J., Zyphur, M. J., \& Zhang, Z. 2010. A general multilevel SEM framework for assessing multilevel mediation. Psychological Methods, 15(3): 209-233.

Rest, J., Narvaez, D., Bebeau, M. J., \& Thoma, S. 1999. Postconventional moral thinking: A neo-Kohlbergian approach. Mahwah, NJ: Lawrence Erlbaum.

Reynolds, M. 1998. Reflection and critical reflection in management learning. Management Learning, 29(2): 183-200.

Reynolds, S. J. 2008. Moral attentiveness: Who pays attention to the moral aspects of life? Journal of Applied Psychology, 93(5): 1027-1041.

Reynolds, S. J., \& Ceranic, T. L. 2007. The effects of moral judgment and moral identity on moral behavior: An empirical examination of the moral individual. Journal of Applied Psychology, 92(6): 1610-1624.

Roberts, B. W. 1997. Plaster or plasticity: Are adult work experiences associated with personality change in women? Journal of Personality, 65: 205-232

Roberts, B. W., Walton, K. E., \& Viechtbauer, W. 2006. Patterns of mean-level change in personality traits across the life course: A meta-analysis of longitudinal studies. Psychological Bulletin, 132: 1-25.

Schaubroeck, J. M., Hannah, S. T., Avolio, B. J., Kozlowski, S. W. J., Lord, R. G., Treviño, L. K., Dimotakis, N., \& Peng, A. C. 2012. Embedding ethical leadership within and across organization levels. Academy of Management Journal, 55(5): 1053-1078.

Schneider, B. 1987. The people make the place. Personnel Psychology, 40(3): 437-453.

Shao, R., Aquino, K., \& Freeman, D. 2008. Beyond moral reasoning: A review of moral identity research and its implications for business ethics. Business Ethics Quarterly, 18(4): 513-540.

Smith, I. H., Aquino, K., Koleva, S., \& Graham, J. 2014. The moral ties that bind... Even to out-groups: The interactive effect of moral identity and the binding moral foundations. Psychological Science, 25(8): 1554-1562.

Sperber, A. D., Devellis, R. F., \& Boehlecke, B. (1994). Cross-cultural translation: Methodology and validation. Journal of Cross-Cultural Psychology, 25(4): 501-524.

Treviño, L. K. 1986. Ethical decision making in organizations: A person-situation interactionist model. Academy of Management Review, 11(3): 601-617. 
Treviño, L. K. \& Brown, M. 2005. The role of leaders in influencing unethical behavior in the workplace. In Kidwell, R. \& Martin, C. (Eds.), Managing Organizational Deviance: 69-87. Thousand Oaks, CA: Sage.

Treviño, L. K., den Nieuwenboer, N. A., \& Kish-Gephart, J. J. 2014. (Un)ethical behavior in organizations. Annual Review of Psychology, 65: 635-660.

Treviño, L. K., Weaver, G. R., \& Reynolds, S. J. 2006. Behavioral ethics in organizations: A review. Journal of Management, 32: 951-990.

van Gils, S., Van Quaquebeke, N., van Knippenberg, D., van Dijke, M., \& De Cremer, D. 2015. Ethical leadership and follower organizational deviance: The moderating role of follower moral attentiveness. The Leadership Quarterly, 26(2): 190-203.

Watson, D., Clark, L. A., \& Tellegen, A. 1988. Development and validation of brief measures of positive affect and negative affect: The PANAS scales. Journal of Personality and Social Psychology, 54(6): 1063-1070.

Weaver, G. R. 2006. Virtue in organizations: Moral identity as a foundation for moral agency. Organization Studies, 27(3): 341-368.

Whetten, D. 2009. An examination of the interface between context and theory applied to the study of Chinese organizations. Management \& Organization Review, 5(1): 29-55.

Whitaker, B. G., \& Godwin, L. N. 2013. The antecedents of moral imagination in the workplace: A social cognitive theory perspective. Journal of Business Ethics, 114(1): 61-73.

Zhu, W., Avolio, B. J., Riggio, R., \& Sosik, J. 2011. The effect of authentic transformational leadership on follower and group ethics. The Leadership Quarterly, 22(5): 801-817.

Zhu, W., He, H., Treviño, L., Chao, M., \& Wang, W. 2015. Ethical leadership and follower voice and performance: The role of follower identifications and entity morality beliefs. The Leadership Quarterly, 26: 702-718. 